\title{
Efficacy of "Acceptance and Commitment Therapy" Psychological Nursing in a Stroke Patient
}

\author{
Xinyu Wang1, Yune Liư ${ }^{2}$, Fang Peng1, Jie Chen ${ }^{2 *}$ \\ ${ }^{1}$ Department of Medicine, Yangtze University, Jingzhou, China \\ ${ }^{2}$ Department of Characteristic Medical Center of PLA Rocket Army, Beijing, China \\ Email: *chenjie681226@sina.cn
}

How to cite this paper: Wang, X.Y., Liu, Y.E, Peng, F. and Chen, J. (2020) Efficacy of "Acceptance and Commitment Therapy" Psychological Nursing in a Stroke Patient. Yangtze Medicine, 4, 293-301. https://doi.org/10.4236/ym.2020.44027

Received: December 15, 2019

Accepted: September 27, 2020

Published: September 30, 2020

Copyright $\odot 2020$ by author(s) and Scientific Research Publishing Inc. This work is licensed under the Creative Commons Attribution International License (CC BY 4.0).

http://creativecommons.org/licenses/by/4.0/ (c) (i) Open Access

\begin{abstract}
Objective: To summarize 1 case of ACT (Acceptance and Commitment Therapy, as "ACT") psychological nursing clinical experience. Method: ACT Application for psychological nursing, provides detailed program guidance for psychological care. Results: Sleep quality, psychological flexibility and self-management ability of the patient have been improved. Conclusion: It's the first time to apply ACT to the psychological nursing for a stroke patient, which has achieved good results; it provides a detailed clinical experience as guidance for the development of psychological nursing; it also provides a clinical basis for the follow-up exploration of psychological nursing technology model.
\end{abstract}

\section{Keywords}

Stroke, Psychological Nursing, Acceptance and Commitment Therapy, Sleep Quality, Psychological Flexibility, Self-Management Ability

\section{Introduction}

According to the World Health Organization, stroke is the second leading cause of death and the third leading cause of disability worldwide [1]. In recent years, due to its high mortality and disability, serious burden has been taken for patients, their families and society, but its negative emotions, such as anxiety, depression, emotional imbalance, anger tendency and so on, are easy to ignore. Patients can't accept the status quo fully, make changes or endure efforts to achieve goals and get values, that is mental flexibility [2] declining. It leads to a series of problems to affect the prognosis for patients, like insomnia, refuse rehabilitation 
training and so on. Although psychological nursing develops widely and deeply in China, the clinical nurses still have many problems in the mental nursing knowledge, ability and the initial implementation of psychological care; they meet difficulties. Therefore clinical adverse events are common because of psychological neglect, and there isn't a detailed and professional clinical case for psychological nursing [3] [4] [5] [6]. The nurse in our hospital, who has double degrees in nursing and psychology, accepted the face-to-face training of Steven C. Haye (the founder of Acceptance and Commitment Therapy, ACT). She has explored the combination of psychological treatment methods and clinical nursing experience after the observation on stroke unit patients, used ACT to psychological care for middle-aged stroke patients while cooperating with doctors for active treatment, to compare the results of psychological assessment before and after, that is, to use their own before-after study experimental methods to verify whether this method is effective, and the effect is significant. Therefore, select a representative nursing case to explain the operation process of psychological nursing in more detail below.

\section{Materials and Methods}

\subsection{Clinical Materials}

A patient, male, 58 years old, high school diploma, veteran, stroke duration of more than 10 months, has suffered from stroke in January 2018 without other disease histories. He was transferred from the emergency department to our department (Stoke Unit) because of fainting suddenly on November 24, 2018. His CT scan showed multiple lacunar cerebral infarctions in the brain and he was diagnosed as acute ischemic stroke. After active treatment, his condition was stable on December 2, 2018, without conscious disorder and cognitive impairment, but gait instability and right limb movement limited was happened. The right side of his body was in the first III stages (early joint movement)for The Brunnstrom Stroke Recovery Grade, the right upper limb can do cooperative movement at will, grasp and pinch hook shape, but the fingers can't extend; the right lower limb had cooperative flexion in hip, knee and ankle in sitting and standing position. The score of Carr-shepherd Motor Function Evaluation is 17, he had moderate dyskinesia. The doctor suggested him do rehabilitation training 2 hours every day, infusion therapy with drugs for stroke such as butylphthalide, and routine nursing including monitoring vital signs and intravenous infusion as advised by the doctor. When the nurse made ward visiting on December 3, 2018, she found that the patient was conscious and in poor spirits and communicated with the patient and his family actively. Patient complained that he felt anxiety, fear and insomnia; his family said he became silent, avoided talking to others, and refused relatives and friends to visit him.

\subsection{Method of Psychological Nursing}

At present, the main method of professional psychological intervention is Cog- 
nitive Behavioral Therapy (for short as CBT), that is, through psychological counseling, interviews, sand tables, pictures and other ways to change the cognition to change the behavior of patients, but the system reviews show many kinds of results for stroke patients who have mood disorders, and there is no conclusive evidence to show that it works; its psychological support for patients is also limited, and the period, 12 times psychological interventions as a cycle generally, is too long; it's limited to cognitive changes that make individual cognitive burden heavier possibly, even influence the effects of intervention [7] [8] [9]. "Acceptance and Commitment Therapy" (for short as ACT) has been used in this case, a new method of psychological intervention, which based on science and Relational Theoretical Framework and proposed in 1999 by Steven c. Hayes, an American psychologist [10]. The ACT theory includes 6 parts: flexible attention to the present moment, acceptance, cognitive defusion, self-as-context, committed action, valuing [11]. Relevant research results show that, it not only improves physical function, but also improves a range of mental health problems [12]. The difference between CBT and ACT is that ACT encourages people to accept the facts not try to change, and psychological flexibility improved as the final aim of ACT. Many domestic researches [13]-[18], using ACT to relieve mental health problems for cancer patients, COPD patients, diabetics, postpartum depression infertility and their families, show that it can improve them psychological flexibility, thus improve them sleep quality and self-management ability. Many studies at home and abroad have shown that, to some extent, psychological flexibility reflects mental health level [19]. But it doesn't be used in stoke patients, and there isn't a case described in more detail to guide clinical using, thus this case dose it.

\subsection{Psychological Assessment}

\subsubsection{Self-Management Behavior Rating Scale for Stroke Patients}

Self-management is an act [19], which improves patients' health through managing some behaviors during the treatment of their illnesses, in order to reduce the influences of illness on social function, emotions and relationships. The scale [20] has 50 entries in 7 dimensions, the total score is 50 to 255, the score higher, the self-management behavior ability better; the Cronbach's $\alpha$ is 0.83 .

\subsubsection{Pittsburgh Sleep Quality Index, PSQI}

The scale [21] is applicable to the evaluation of sleep quality for patients with sleep disorders and mental disorders, as well as the evaluation of sleep quality for general people; the total score is 0 to 21 points, the score higher, the sleep quality worse; the Cronbach's $\alpha$ is 0.845 .

\subsubsection{Acceptance and Action Questionnaire-II, AAQ-II}

The questionnaire is used to measure the degree of "empirical avoidance", there are 7 items in the scale, with points from 1 (never) to 7 (always), the score higher, the degree deeper of empirical avoidance; the Cronbach's $\alpha$ is 0.84 [22] [23] [24]. "Empirical avoidance" [25] is an act that people attempts to change the 
form, frequency, or sensitivity of their internal experiences (such as thoughts, emotions, and somatosensory sensations) in their minds, even if doing it can lead to actions that are inconsistent with their personal values or goals (such as giving up pursuing a long-term goal in order to avoid anxiety).

\subsubsection{Cognitive Fusion Questionnaire, CFQ}

"Cognitive Fusion" is the tendency of people's behavior to be excessively controlled by language rules and thought content, which will enable individuals to automatically extract the literal meaning of thought events, and thus unable to guide their behavior with the direct experience of the "here and now" [26]. There are 9 items in the scale [27], with points from 1 (never) to 7 (always), the score higher, the degree deeper of cognitive fusion; the Cronbach's $\alpha$ is 0.89 .

\section{Psychological Nursing Processes}

\subsection{Interview}

Uses ACT for analysis; results are listed in Figure 1.

\subsection{Application Details}

\subsubsection{Cognitive Defusion}

Soft music is used to guide the patient to recall the terrible inner events and compare it or them to "the monster on the bus". The patient is the bus driver and there are many passengers on the bus. At this time, he complained of "monster" as "permanent hemiplegia".

\subsubsection{Acceptance}

He was guided to imagine the route of the bus, with each passenger having his or her own station to get on or off. It was impossible to predict which passengers

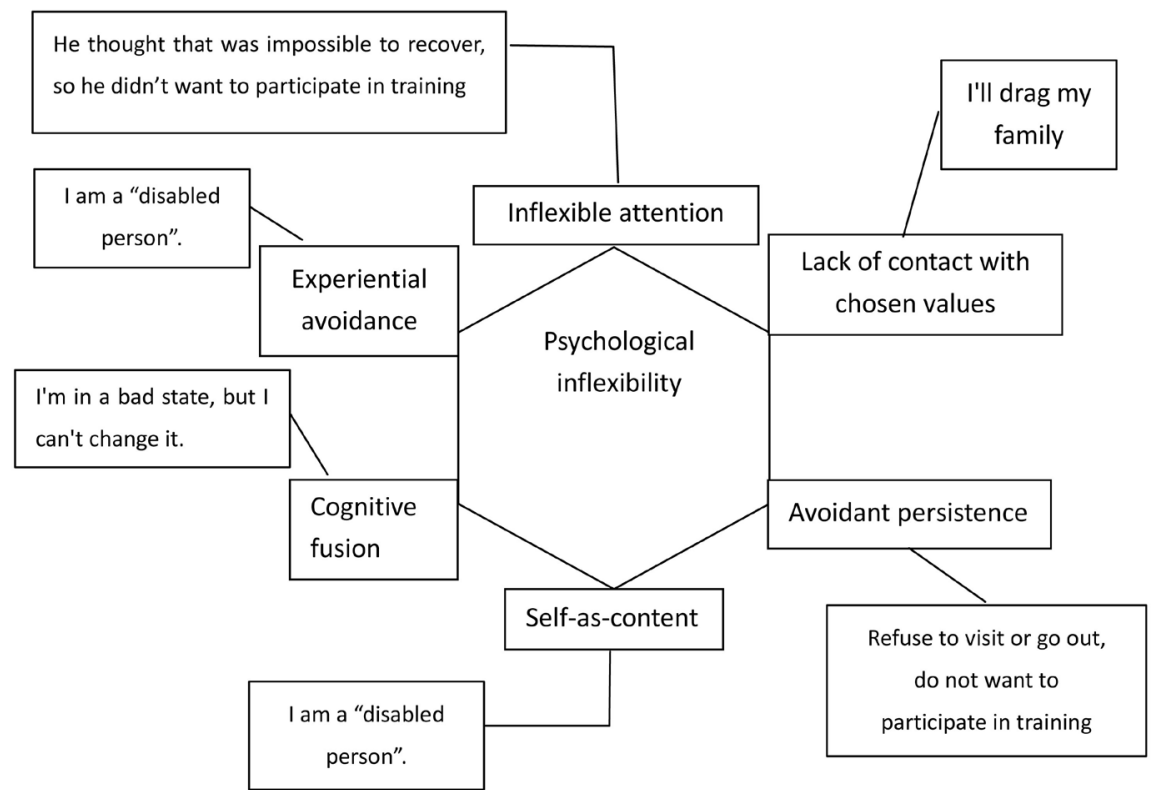

Figure 1. Results of interview. 
would get on. There may be hidden "monsters" in it, but anyway the car will arrive at the terminal.

\subsubsection{The Present Moment}

Guide him to imagine the scene in the car, "monster" suddenly appeared, what will the driver do? He replied that there will be panic in the car and delay the journey, and as the driver, he should ensure the passengers' safety, find ways to subdue the "monster", reduce the loss, maximize the optimization results, and ensure passengers to the station safely, and to the terminal finally.

\subsubsection{Self-as-Context}

Guide him to imagine that if there were other bus drivers saw such a bus appear at the terminal, how would others feel? Others admire or ridicule? "Admire". He answered.

\subsubsection{Valuing}

Ask him: what will happen if you had abandoned the car? The bus is like your body. It can be your life. Some things happen unexpectedly, but after the occurrence, you can choose the result. You can abandon the car, or face it and try to solve.

\subsubsection{Committed Action}

Guide him to talk in detail about how he would address this situation if he were the driver. What specific goals are achieved? According to "each passenger will have a safe arrival station" and "to the destination", guide him to make rehabilitation plans and design simple and convenient rehabilitation actions. Such as picking fruit from large to small, he still can implement after discharge. Determine the goal of phased rehabilitation, as well as the ultimate goal. The nurse and his family should be based on trust and guidance, supplemented by scientific and technological tools for telephone video follow-up and exchange program progress, rather than absolute review, to avoid causing psychological pressure for patients.

\subsection{Results}

Measurement results of these scales before and after ACT psychological nursing are listed in Table 1.

Table 1. Results of ACT psychological nursing.

\begin{tabular}{cccc}
\hline & $2018-12-3$ & $2018-12-15$ & $2019-1-15$ \\
\hline PSQI & 16 & 10 & 9 \\
Self-management & 142.59 & 182.59 & 205.17 \\
AAQ-II & 30 & 22 & 15 \\
CFQ & 59 & 39 & 23
\end{tabular}




\section{Discussion}

The psychological load of stroke patients in rehabilitation period is heavy, especially for the elderly patients with impaired limb function, the rehabilitation period is a long and slow process, so should pay more attention to psychological nursing. Due to psychological rigidity, most patients are unwilling to accept rehabilitation training, self-denial, self-abandonment and other negative emotions, resulting in poor sleep quality and self-management ability, thus affecting the quality of life and even causing secondary stroke [28]. In this case, ACT was applied for psychological nursing for stroke patients at the first time with innovative methods, clear operating regulations, and detailed procedures recorded and displayed to provide guidance for the implementation of clinical psychological nursing. ACT psychological nursing greatly improved patients' sleep quality and psychological flexibility, improved self-management ability, and improved quality of life, making patients pay attention to the moment, take the initiative to set action goals, and in the behavior to achieve the goal of perseverance, so as to find self-value. There are also many domestic research [29] [30] [31] [32] [33] is applied to the patient's psychological nursing, such as cancer patients and their families, patients with COPD, postpartum depression and mental health problems such as infertility crowd, to improve diabetes self-management ability, mental flexibility. And ACT psychological nursing intervention cycle is short, without trauma.

This study shows that ACT Application can significantly improve patients' self-management ability, which is consistent with the findings of other scholars. However, at present, there are few clinical nurses with professional psychological background, and due to the heavy clinical work, they tend to ignore the further study of psychological knowledge, and relatively lack of professional nursing psychology education, so the implementation of professional ACT psychological nursing is facing certain difficulties, so it is urgent to train a batch of psychological nursing specialist nurses. Some studies have shown that no statistical significance about ACT was used by psychologists and trained ordinary medical workers for patients [34]. This suggests that we can train more medical workers to master ACT intervention technology, train professional psychological nursing teams, and make clinical psychological nursing more standardized.

\section{Summary}

To sum up, patients have heavy psychological burden in the rehabilitation period of stroke, especially with impaired limb function. The application of ACT can improve patients' psychological flexibility, thus improving the quality of sleep and self-management ability. ACT also can be applied to the psychological nursing of patients with other diseases skillfully, to provide reference for the standardized development of psychological nursing in China.

\section{Funding Project}

Capital clinical characteristic application research (Z181100001718041). 


\section{Conflicts of Interest}

The authors declare no conflicts of interest regarding the publication of this paper.

\section{References}

[1] The Top 10 Causes of Death 2017. http://www.who.int/mediacentre/factsheets/fs310/en

[2] Hayes, S.C., Luoma, J.B., Frank, W., et al. (2005) Acceptance and Commitment Therapy: Model, Processes and Outcomes. Behavior Research and Therapy, 44, 1-25. https://doi.org/10.1016/j.brat.2005.06.006

[3] Niu, F.X., Hu, F.R. and Tian, Y.X. (2008) Investigation and Analysis on the Status Quo of Clinical Nurses' Psychological Nursing Consciousness in the Top Three Hospitals. Chinese General Practice Nursing, 16, 736-737.

[4] Liu, J.J. (2019) Investigation and Analysis of Nurses' Psychological Nursing Knowledge, Consciousness and Implementation Status. Electronic Journal of Clinical Medical Literature, 6, 181.

[5] Jin, J.F. (2015) New Progress in Psychological Nursing Research. The Journal of Medical Theory and Practice, 28, 1724-1726.

[6] Liu, T.F., Zhang, A.H., Yan, A.Y., et al. (2017) Research Status Quo and Hotspot Analysis of Psychological Nursing for Elderly in the World. Nursing Research of China, 31, 3653-3658.

[7] Hackett, M.L., Anderson, C.S., House, A., et al. (2008) Interventions for Treating Depression after Stroke. Cochrane Database of Systematic Reviews, 4, 1-95. https://doi.org/10.1002/14651858.CD003437.pub3

[8] Rasquin, S.M.C., Van De Sande, P., Praamstra, A.J., et al. (2008) Cognitive-Behavioral Intervention for Depression after Stroke: Five Single Case Studies on Effects and Feasibility. Neuropsychological Rehabilitation, 19, 208-222.

https://doi.org/10.1080/09602010802091159

[9] Hackett, M.L., Anderson, C.S., House, A.O, et al. (2009) Interventions for Preventing Depression after Stroke. Stroke, 40, e485-e486. https://doi.org/10.1161/STROKEAHA.109.547042

[10] Herbert, J.D., Hayes, S.C., Strosahl, K.D. and Wilson, K.G. (1999) Acceptance and Commitment Therapy: An Experiential Approach to Behavior Change. Guilford Press, New York.

[11] Bennett, R. and Oliver, J. (2018) Acceptance and Commitment Therapy. Taylor and Francis, Boca Raton. https://doi.org/10.4324/9781351056144

[12] Spidel, A., Lecomte, T., Kealy, D., et al. (2018) Acceptance and Commitment Therapy for Psychosis and Trauma: Improvement in Psychiatric Symptoms, Emotion Regulation, and Treatment Compliance Following a Brief Group Intervention. Psychology and Psychotherapy. Theory, Research and Practice, 91, 248-261. https://doi.org/10.1111/papt.12159

[13] Gong, Y., Cui, L.Q. and Jiang, W.L. (2015) Effects of Acceptance and Realization Therapy on Anxiety and Depression in Cancer Patients. Nursing Practice and Research, 12, 142-143.

[14] Wang, R., Liu, Y.J., Yong E.H., et al. (2017) Effects of Acceptance and Commitment Therapy on Anxiety and Depression in Infertile Patients and Their Quality of Life. Hebei Medical Journal, 39, 3430-3432. 
[15] Lu, D. and Fan, J.Q. (2017) Effects of Routine Nursing Combined with Acceptance and Commitment Therapy on Depression, Self-Efficacy and Self-Esteem in Postpartum Depression Patients. Sichuan Mental Health, 30, 253-255.

[16] Wang, Y. (2016) Application of Admission and Commitment Therapy in Self-Management of Patients with Chronic Obstructive Pulmonary Disease (COPD). Guide of China Medicine, 14, 198-199.

[17] Ma, K.Y., Jiang, W.L., Liang, W.X., et al. (2019) Effect of Admission and Commitment Therapy on Posttraumatic Growth in Patients Undergoing Urethroplasty. Journal of Nursing Science, 34, 73-75+86.

[18] He, H.J. (2018) Acceptance Commitment Therapy in Self-Management of Patients with Type 2 Diabetes. Nanchang University, Nanchang.

[19] Kashdan, T.B. and Jonathan, R. (2010) Psychological Flexibility as a Fundamental Aspect of Health. Clinical Psychology Review, 30, 865-878. https://doi.org/10.1016/j.cpr.2010.03.001

[20] Swerissen, H., Belfrage, J., Weeks, A., et al. (2006) A Randomized Control Trial of a Self-Management Program for People with a Chronic Illness from Vietnamese, Chinese, Italian and Greek Backgrounds. Patient Educe Counts, 64, 360-368. https://doi.org/10.1016/j.pec.2006.04.003

[21] Wang, Y.J. (2012) Research on the Construction and Application of Stroke Self-Management Project. Chengdu University of Chinese Medicine, Chengdu.

[22] Lu, T.Y., Li, Y., Xia, P., et al. (2014) Reliability and Validity Analysis of Pittsburgh Sleep Quality Index. Chongqing Medical, 43, 260-263.

[23] Fledderus, M., et al. (2012) Further Evaluation of the Psychometric Properties of the Acceptance and Action Questionnaire-II. Psychological Assessment, 24, 925-936. https://doi.org/10.1037/a0028200

[24] Bond, F.W., Hayes, S.C., Baer, R.A., et al. (2011) Preliminary Psychometric Properties of the Acceptance and Action Questionnaire-II: A Revised Measure of Psychological Inflexibility and Experiential Avoidance. Behavior Therapy, 42, 676-688. https://doi.org/10.1016/j.beth.2011.03.007

[25] Cao, J., Ji, Y. and Zhu, Z.H. (2013) The Second Chinese Version of the Acceptance and Action Questionnaire Assessed the Reliability and Validity of College Students. Chinese Mental Health Journal, 27, 873-877.

[26] Hayes, S.C., Wilson, K.G., Gifford, E.V., et al. (1996) Experimental Avoidance and Behavioral Disorders: A Functional Dimensional Approach to Diagnosis and Treatment. Journal of Consulting and Clinical Psychology, 64, 1152-1168. https://doi.org/10.1037/0022-006X.64.6.1152

[27] Zhang, W.C., Ji, Y., Li, X., et al. (2014) Reliability and Validity Analysis of the Chinese Version of Cognitive Fusion Questionnaire. Chinese Mental Health Journal, 28, 40-44.

[28] Zhang, S.M., Ji, J., Hu, L.Z., et al. (2019) A Meta-Analysis of Randomized Controlled Trials of Auricular Therapy for Insomnia after Stroke. Academic Journal of Shanghai University of Traditional Chinese Medicine, 33, 10-18 + 23.

[29] Huang, C.M., Li, J., Lu, H.Y., et al. (2019) A Clinical Study of Acceptance and Commitment Therapy Combined with Paroxetine in the Treatment of Depression after Painless Childbirth. Academic Journal of Guangzhou Medical University, 47, 74-76.

[30] Huang, G.Q. (2019) Effects of Acceptance and Commitment Therapy on Mental Resilience of Caregivers of Patients with Severe Craniocerebral Trauma. Electronic 
Journal of Practical Clinical Nursing Science, 4, 146-147.

[31] Gong, R.F., Liu, J.E. and Wang, Q.L. (2019) Effect of Acceptance Commitment Therapy on Cancer Recurrence fear in Patients with Recurrent Oral Cancer. Journal of Nursing Science, 34, 84-86+102.

[32] Zhao, Y.X. and Zhong, Q.L. (2019) Advances in the Application of Acceptance and Commitment Therapy in Chronic Disease Management. Nursing Research, 33, 3179-3181.

[33] He, H.J. (2018) Application of Acceptance and Commitment Therapy in Self-Management of Patients with Type 2 Diabetes Mellitus. Nanchang University, Nanchang.

[34] Thomas, R., Lorraine, B., Helen, B., et al. (2018) Development and Evaluation of Acceptance and Commitment Therapy Delivered by Psychologists and Non-Psychologists in an NHS Community Adult Mental Health Service: A Preliminary Analysis. Behavioural and Cognitive Psychotherapy, 46, 121-127.

https://doi.org/10.1017/S1352465817000285 